\title{
Proteomics Complementation of the Rat Uterotrophic Assay for Estrogenic Endocrine Disruptors: A Roadmap of Advancing High Resolution Mass Spectrometry-Based Shotgun Survey to Targeted Biomarker Quantifications
}

\author{
Laszlo Prokai *(D), Fatima Rahlouni ${ }^{D}$, Khadiza Zaman (D), Vien Nguyen and Katalin Prokai-Tatrai \\ Department of Pharmacology and Neuroscience, University of North Texas Health Science Center, \\ Fort Worth, TX 76107, USA; Fatima.Rahlouni@my.unthsc.edu (F.R.); Khadiza.Zaman@unthsc.edu (K.Z.); \\ Vien.Nguyen@unthsc.edu (V.N.); Katalin.Prokai@unthsc.edu (K.P.-T.) \\ * Correspondence: Laszlo.Prokai@unthsc.edu; Tel.: +1-817-735-2206
}

\section{check for} updates

Citation: Prokai, L.; Rahlouni, F.; Zaman, K.; Nguyen, V.; Prokai-Tatrai, K. Proteomics Complementation of the Rat Uterotrophic Assay for Estrogenic Endocrine Disruptors: A Roadmap of Advancing High Resolution Mass Spectrometry-Based Shotgun Survey to Targeted

Biomarker Quantifications. Int. J. Mol. Sci. 2021, 22, 1686. https://doi.org/ 10.3390/ijms22041686

Academic Editor: Hartmut Schlüter Received: 31 December 2020

Accepted: 4 February 2021

Published: 8 February 2021

Publisher's Note: MDPI stays neutral with regard to jurisdictional claims in published maps and institutional affiliations.

Copyright: (c) 2021 by the authors. Licensee MDPI, Basel, Switzerland. This article is an open access article distributed under the terms and conditions of the Creative Commons Attribution (CC BY) license (https:// creativecommons.org/licenses/by/ $4.0 /)$.
Abstract: The widely used rat uterotrophic assay to assess known and potential estrogenic compounds only considers uterine weight gain as endpoint measurement. To complement this method with an advanced technology that reveals molecular targets, we analyzed changes in protein expression using label-free quantitative proteomics by nanoflow liquid chromatography coupled with high-resolution mass spectrometry and tandem mass spectrometry from uterine protein extracts of ovariectomized rats after daily $17 \beta$-estradiol exposure for five days in comparison with those of vehicle-treated control animals. Our discovery-driven study revealed 165 uterine proteins significantly regulated by estrogen treatment and mapped by pathway analyses. Estrogen-regulated proteins represented cell death, survival and development, cellular growth and proliferation, and protein synthesis as top molecular and cellular functions, and a network found with the presence of nuclear estrogen receptor(s) as a prominent molecular node confirmed the relevance of our findings to hormone-associated events. An exploratory application of targeted proteomics to bisphenol A as a well-known example of an estrogenic endocrine disruptor is also presented. Overall, the results of this study have demonstrated the power of combining untargeted and targeted quantitative proteomic strategies to identify and verify candidate molecular markers for the evaluation of endocrine-disrupting chemicals to complement a conventional bioassay.

Keywords: endocrine disruption; rat uterus; estrogen-regulated proteins; $17 \beta$-estradiol; liquid chromatography-mass spectrometry; label-free proteomics; high resolution mass spectrometry; protein networks; targeted proteomics; bisphenol A

\section{Introduction}

Endocrine-disrupting chemicals (EDCs) are a class of agents that interfere with the biological actions of hormones, and there has been significant public concern about their adverse effect on the environment and on human health [1]. EDCs are broadly categorized according to the hormones that they interfere with estrogens, androgens, or thyroid hormone activities. The US Environmental Protection Agency (EPA) has set up the Endocrine Disruptor Screening Program to test the tens of thousands of chemicals for suspected endocrine disruption based on a directive from section 408(p) of the Federal Food, Drug and Cosmetic Act, the Food Quality Protection Act and the Safe Drinking Water Act of 1996 to develop a chemical screening program using appropriately validated methods to determine whether substances may have hormonal effects [2-4]. Agents that mimic the effect of endogenous human estrogens are the most recognized class of EDCs.

For the vast majority of these compounds that are tested for estrogenic effects in the uterus, the "gold standard" in vivo uterotrophic rat assay is utilized, and they may be tested in vitro on rodent, yeast, and human cell lines as part of the complementary battery 
of assays implemented in the EPA's two-tier testing program [2-10]. The uterotrophic assay uses either sexually immature female rats or adult ovariectomized (OVX) female rats, where there is no significant source of endogenous estrogens. In either version of the assay, multiple doses of a test compound are administered over consecutive days (a minimum of three days either orally or subcutaneously). Agents that do have estrogenic effects cause uterotrophic response due to imbibition of water and growth of the uterine cells. Statistically significant uterine weight increases compared to controls give a positive result.

The current in vitro and in vivo methods are not without limitations. The cell lines are not properly able to recapitulate the in vivo environment of the uterus within the body. On the other hand, the rat uterotrophic assay merely considers the uterine weight gain as an endpoint of estrogenicity without taking into account all factors that play a role in exerting an estrogenic effect on the organ and body [9-15]. The need for advanced testing to evaluate the safety of tens of thousands of xenobiotics in the environment has been brought to light as the traditional testing methodologies do not adequately address the complexity of their risks on human health [4]. Therefore, complementing the uterotrophic assay with suitable molecular-level endpoint data could diminish the chances of dismissing potential estrogenic EDCs from further investigations because they do not meet statistical significance criteria for organ weight gain only, especially in studies involving a small number of animal subjects in the treatment groups. Such multiple-measure assessment that includes biological information could also justify further targeted studies to identify specific links between chemical interactions and toxicological effects. These targeted approaches could not only assist screening of the already narrowed down list of candidate EDCs but also be used in helping prioritize them for additional testing to assess their estrogenicity.

Transcriptome-level changes that take place early after exposure to $17 \beta$-estradiol $\left(E_{2}\right.$, the main human estrogen) and estrogenic EDCs have been investigated [16-19]. However, the focus of these studies has been on, e.g., the understanding of developmental changes in the uterus and the effects on fertility [20,21], or exploration of systemic effects due to environmental contaminants [22,23]. A limited number of reports are available about the identification of estrogen-regulated proteins in the rodent uterus using proteomics [24,25], and only one of them has presented tangible results focusing on uterine proteins regulated by $\mathrm{E}_{2}$ exposure in a mouse model [24]. Critical data in this regard have not been available for potential use in the context of the rat uterotrophic assay. Proteomics, the large-scale study of a proteome (proteins in a cell or tissue) of an organism, has become an increasingly mature methodology relying mostly on mass spectrometry and its advances [26-32]. Mass spectrometry-based proteomics has two branches: discovery-driven (or untargeted "shotgun") proteomics and targeted proteomics [33], which is commonly performed sequentially.

Here, we report the identification of proteins regulated by $\mathrm{E}_{2}$ using a quantitative proteomic investigation in the rat uterus first by an untargeted label-free discovery approach based on high resolution (Orbitrap) mass spectrometry (MS) and tandem mass spectrometry (MS/MS) in combination with online nanoflow liquid chromatography (LC). Then, verification of selected markers of estrogenicity is presented along with an exploratory application of targeted proteomics methods to bisphenol A (BPA) as a well-known example of estrogenic EDCs [34]. BPA represents 2,2-bis(4-hydroxyphenyl)propane, a synthetic chemical used to make polycarbonates and epoxy resins on an industrial scale. Biomonitoring studies show that human and animal exposure to BPA is rapid and continuous from the environment [34]. Altogether, this compound is a proven endocrine disruptor that mimics estrogens as a ligand at the cognate receptors thereby altering hormone concentrations and its metabolism.

\section{Results and Discussion}

Discovery-driven proteomic analysis was performed using an adult OVX female rat model, as described for the testing of EDCs using the EPA's uterotrophic assay [14,15]. We adapted a rapid tissue proteomics-based approach used previously for a quantitative survey 
of the impact of E2 on the OVX rat retina [35]. Using the Mascot database search algorithm within Proteome Discoverer (version 2.3), 2683 total protein identifications including 1547 high confidence protein identifications were obtained at the desired false discovery rate (FDR) set to $\leq 1 \%$. However, only 774 proteins (representing 615 protein clusters) passed Scaffold's rigorous validation criteria relying on both Peptide Prophet [36] and Protein Prophet [37] with at least two unique tryptic peptides identified for each protein (Table S1). For label-free quantification (LFQ), we used spectral counting (SC) $[24,35]$ to detect uterine protein expression differences between the E2-treated versus vehicle control groups of OVX rats. Spectral counting is a quantitative method that counts and compares the number of fragment spectra identifying peptides of any protein. Although the technique has been capable of providing reasonable estimates about the extent of changes in protein abundances, they are generally not quantitatively accurate compared to targeted proteomics. Nevertheless, trends (i.e., up- and down-regulation of proteins) can be reliably identified through such label-free quantification [38]. Altogether, spectral counts of 165 proteins were affected significantly by $\mathrm{E}_{2}$ exposure of the uterus; among these 143 were up-regulated and 22 were down-regulated by the hormone (Table S2).

To advance from this list of potential markers of estrogenicity in the rat uterus towards targeted proteomics in the context of the uterotrophic assay, one may focus on selected findings considering previous reports. For example, several of the estrogen-regulated proteins, such as the vitamin D-dependent calcium-binding protein S100G and transglutaminase 2 (TGM2), have been previously reported from mouse transcriptomic studies [14-16]. However, our broader context justified comprehensive bioinformatics to guide the selection of targets. Therefore, we used Ingenuity Pathway Analysis (IPA ${ }^{\circledR}$ ) to find functional interactions between the up- and down-regulated proteins identified in our study. Proteins found to be significantly affected by $E_{2}$ in the OVX rat uterus mapped across ten heuristic IPA $^{\circledR}$ networks (Figures S1-S10). Associated functions of these networks included gene expression, ribonucleic acid (RNA) damage and repair, RNA post-transcriptional modification, protein synthesis, cellular assembly and organization, cellular compromise, drug metabolism, cell morphology, embryonic development, cellular function and maintenance, cellular growth, and proliferation, cancer, connective tissue disorder, etc.-all with relevance to estrogen biology shown, e.g., by the presence of an estrogen receptor (ER) or $E_{2}$ ("beta-estradiol") as a node in two specific networks (Figures S1 and S2). Although other networks were not associated with ER, non-genomic mechanisms of estrogen actions have been well documented and may operate through synergistic or additive effects involving the activation of ER signaling in the context of endocrine disruption [39]. Three networks also overlapped regarding the involved proteins and functions (Figure S11).

In addition, accurate (inclusion) mass screening [40] relying on the acquired raw data from the untargeted shotgun experiments was performed to support the selection of potential uterine markers from bioinformatic analyses involving the list of proteins found to be affected significantly by $E_{2}$ exposure. This approach helped bridge high-resolution mass spectrometry-based untargeted discovery with the targeted assay development done typically by using multiple reaction monitoring (MRM) of peptides by LC-MS/MS on triple quadrupole instruments. The advantage of the high mass accuracy of the Orbitrap ( $>3 \mathrm{ppm}$ for full-scan MS acquisition even without an internal "lock mass") to verify peptides and sequences from an extensive list of candidate proteins is illustrated in Figure 1 and Figures S12-S14 for the selected four rat uterine proteins (upregulated and downregulated by $\mathrm{E}_{2}$ treatment, two proteins each, respectively). When these prioritized candidate proteins were assembled in a heuristic IPA ${ }^{\circledR}$ network shown in Figure 2, associated functions included connective tissue development and function, organ morphology, reproductive system development, and function highly relevant to the uterotrophic activity of estrogen. 
(a)

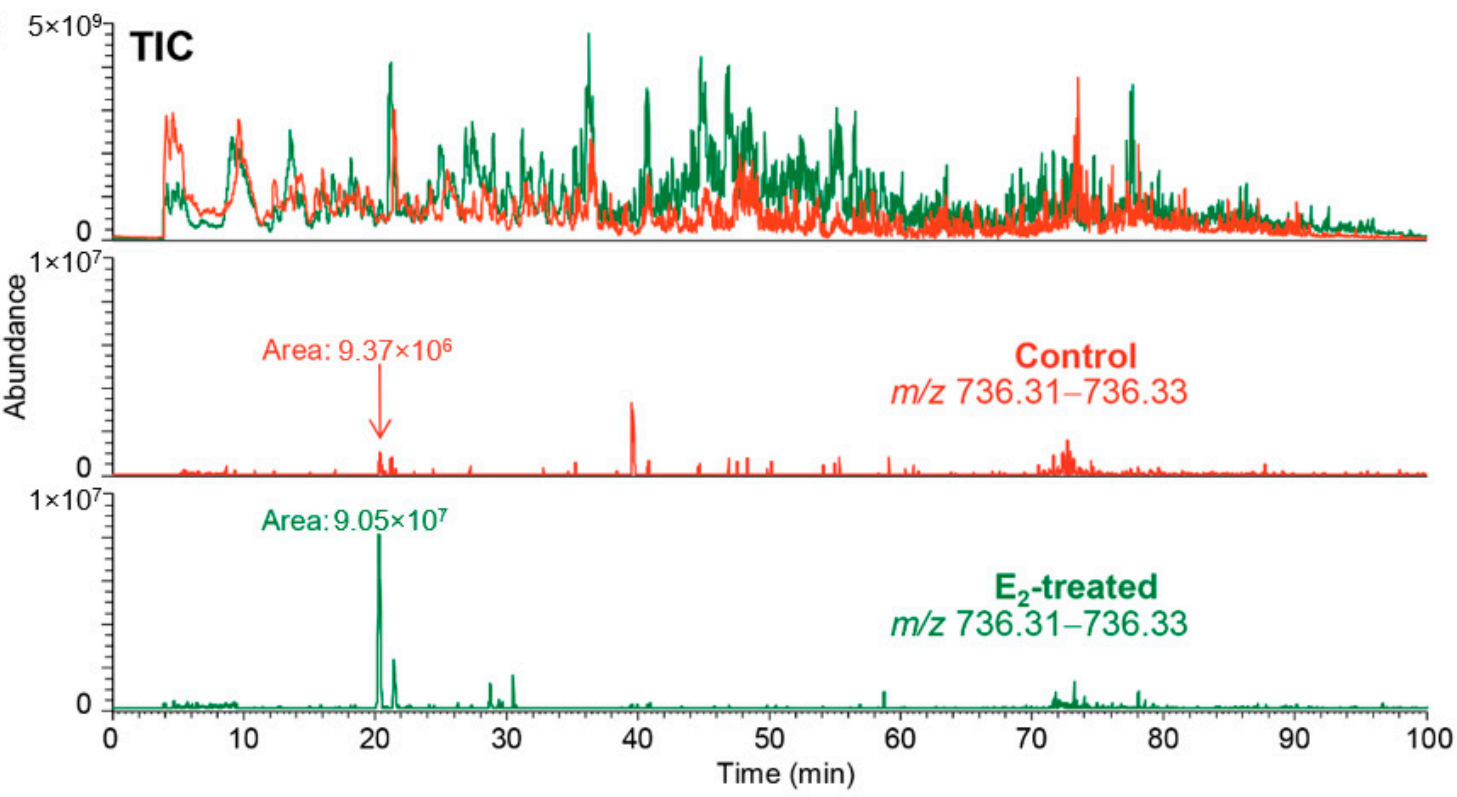

(b)

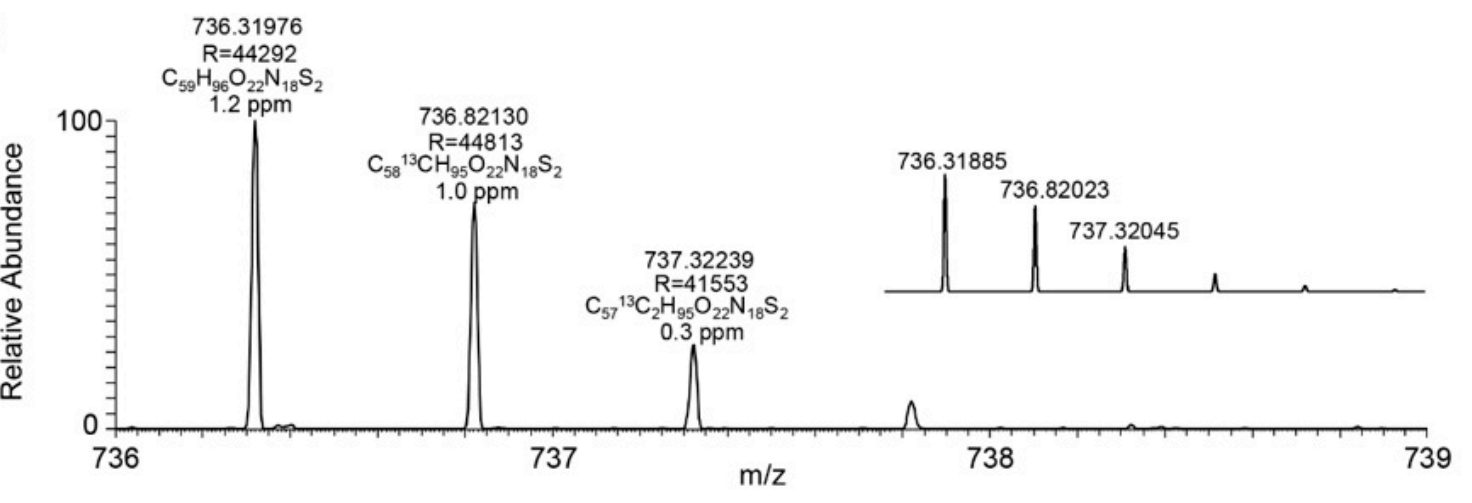

(c)

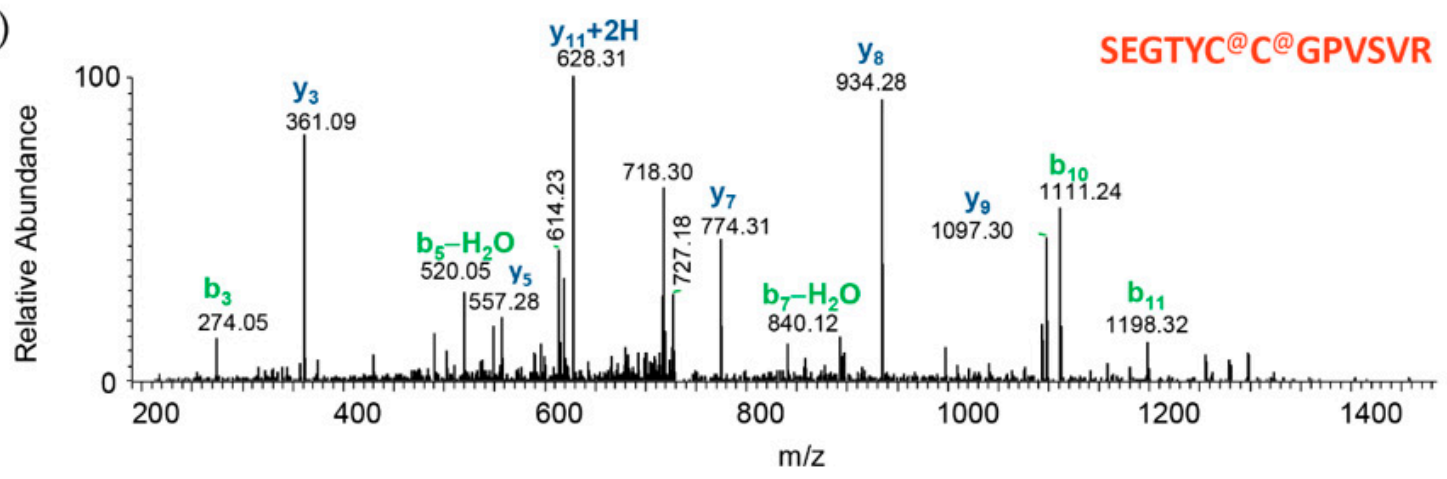

Figure 1. Screening from acquired high mass resolution (Orbitrap) mass spectra during the untargeted shotgun acquisitions for transglutaminase 2 (TGM2) as a prioritized uterine protein marker for targeted assay development. (a) Locating a proteotypic tryptic peptide of TGM2 by accurate mass of its doubly-charged ion $[\mathrm{M}+2 \mathrm{H}]^{2+}(\mathrm{TIC}$ : total-ion chromatogram, brown and green traces: uterus samples from control and E2-treated rat, respectively); (b) Verifying accurate masses and isotope peak distribution of the doubly-charged ions ( $\mathrm{R}$ : mass resolution, inset: theoretical $\mathrm{m} / \mathrm{z}$ and isotope peak distribution); (c) Confirming the peptide sequence SEGTYC ${ }^{@} \mathrm{C}^{@} \mathrm{GPVSVR}$ by the acquired ion-trap tandem mass spectrometry (MS/MS) scan (b and y sequence ions marked according to nomenclature by Roepstorff and Fohlman [41]; $\mathrm{C}^{\circledR}$ is carbamidomethylated cysteine). 

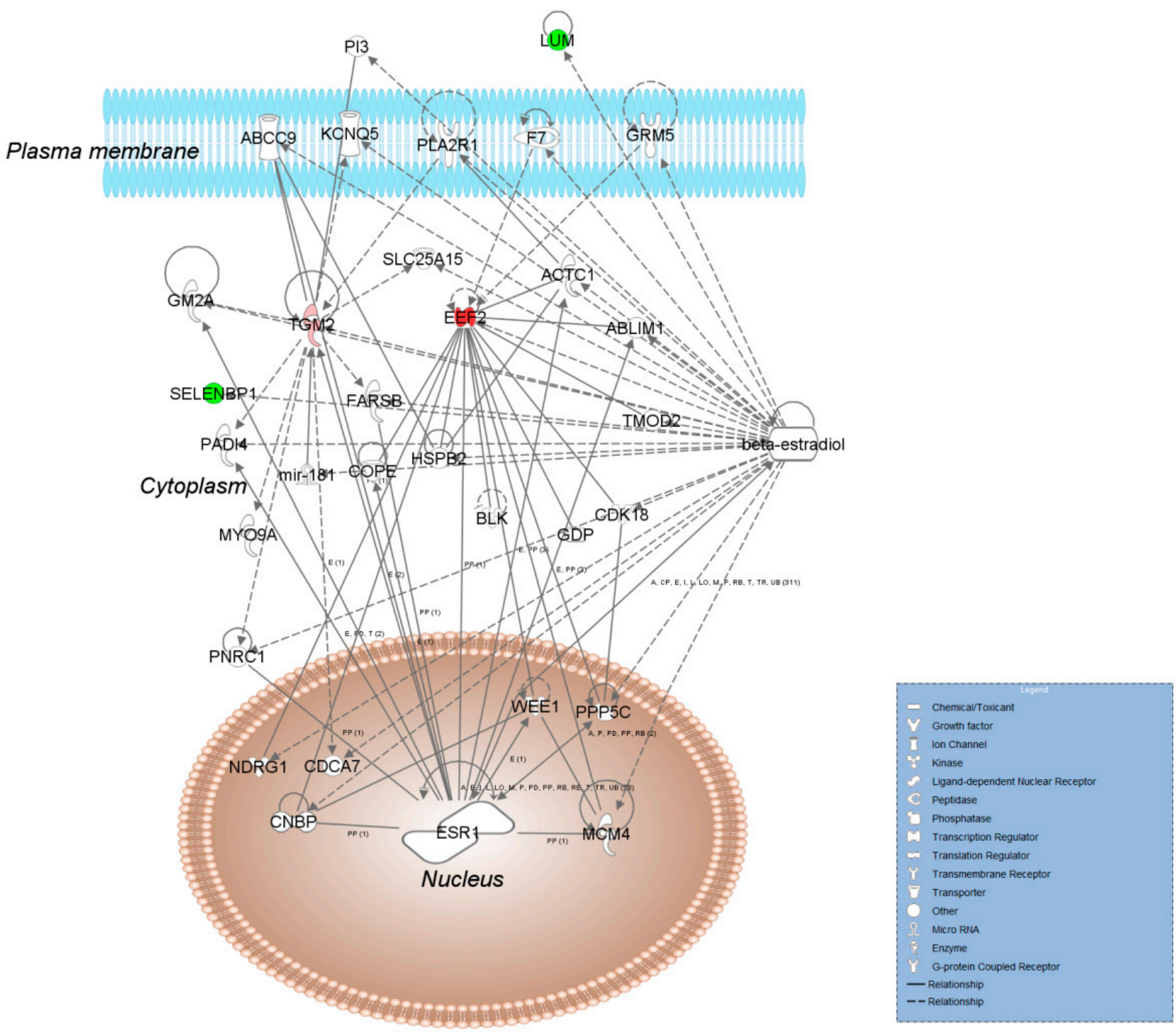

Figure 2. Molecular interaction Ingenuity Pathway Analysis $\left(\mathrm{IPA}^{\circledR}\right)$ network associated with connective tissue development and function, organ morphology, reproductive system development, and function assembled from the $\mathrm{E}_{2}$-regulated uterine proteins TGM2, elongation factor 2 (EEF2), selenium binding protein 1 (SELBP1), and lumican (LUM) in the rat. The shapes (see legend in the blue box) represent molecular classes of the regulated proteins. In the network, red and green colors denote upregulation and downregulation in response to $\mathrm{E}_{2}$ treatment, respectively. The intensity of the color indicates the relative magnitude of fold change in protein expression pattern based on spectral counts. Solid and dashed lines represent direct and indirect interactions, respectively. Abbreviations: ABLIM1, actin binding LIM protein 1; ABCC9, adenosine triphosphate (ATP) binding cassette subfamily C member 9; ACTC1, actin alpha cardiac muscle 1; BLK, proto-oncogene, Src family tyrosine kinase; CDCA7, cell division cycle associated 7; CDK18, cyclin dependent kinase 18; CNBP, CCHC-type zinc finger nucleic acid binding protein; COPE, COPI coat complex epsilon; ESR1, estrogen receptor 1; F7, coagulation factor 7; FARSB, phenylalanyl-tRNA synthetase subunit beta; GDP, guanosine diphosphate; GM2A, ganglioside activator; GRM5, glutamate metabotropic receptor 5; HSPB2, heat shock protein family B (small) member 2; KCNQ5, potassium voltage-gated channel subfamily Q member 5; MCM4, minichromosome maintenance complex component 4; mir, microRNA; MYO9A, myosin IXa; NDRG1, N-myc downstream regulated 1; PADI4, peptidyl arginine deiminase 4; PI3, peptidase inhibitor 3; PLAZR1, phospholipase A2 receptor 1; PNRC1, proline rich nuclear receptor coactivator; PPPP5C, protein phosphatase 5 catalytic subunit; SLC25A15, solute carrier family 25 member 15; TMOD2, tropomodulin 2; WEE1, G2 checkpoint kinase. 
TGM2 is in a class of enzymes that catalyze the crosslinking of proteins by epsilongamma glutamyl lysine isopeptide bonds. This protein was shown to be activated in bovine uteruses and mouse livers [18,42]. TGM2, while being involved in $\mathrm{Ca}^{2+}$-dependent transamidation of proteins, is also involved in roles that are non-enzymatic and not $\mathrm{Ca}^{2+}$-dependent. TGM2 also participates in ATP and GTP hydrolysis, as well as in signal transduction through G-protein coupled receptors. Altogether, this protein potentially plays a critical role in remodeling the cytoskeletal structure and maintaining structural integrity, and variation in its abundance could contribute to the major morphological changes involved with the growth of the uterus upon $\mathrm{E}_{2}$ exposure. In addition to all these enzymatic roles, it also has multiple interactions with protein scaffolds [43]. In vivo using proteomics, TGM2 has not been identified previously as estrogen-regulated. Therefore, our finding is significant given the protein's physiological importance and presence in the interaction networks we show in Figure 2 and Figure S8.

EEF2 belongs to the GTP-binding translational elongation factor family and serves as an important checkpoint regulator. It is essential for protein synthesis, as it catalyzes the GTP-dependent ribosomal translocation step in translation. EEF2 is a well-known up-regulated marker of estrogen exposure $[24,44,45]$ shown previously in mouse uterus and cancer cells. Its expression in the $\mathrm{E}_{2}$-challenged uterus could be explained by the need for an increase in protein syntheses to keep up with the demands of the growth of the organ. This is consistent with our discovery data showing the majority of the estrogen-regulated proteins are activated.

SELENBP1, a protein that binds this trace elemental component of nonconventional amino acids selenocysteine and selenomethionine as well as selenoproteins, may be involved in the sensing of reactive xenobiotics in the cytoplasm and may be involved in intra-Golgi protein transport [46-48]. SELENBP1 expression has been shown by transcriptomics to be downregulated upon $E_{2}$ exposure in the uterus and in cancer cells $[17,49]$. While its role is not fully understood, as a binding protein of selenium it contributes to the maintaining of the redox state of the cell by keeping free selenium concentrations low. Selenium is toxic to the cell in large concentrations yet it is necessary for the functioning of antioxidant selenoproteins. $E_{2}$ exposure could cause a shift in the redox state of the cell and hence could cause a loss in the protective function of SELENBP1. This protein is another novel finding in our study as it has not been shown previously as estrogen-regulated in vivo in the rat uterus using proteomics.

LUM is in the family of small leucine-rich proteoglycans (SLRPs). This protein has been shown to be constitutively expressed and deposited in the extracellular matrix of the mouse uterus in the absence of the ovarian hormones but remodels along the estrous cycle and early pregnancy [50]. LUM modulates synthesis, deposition, and degradation of various molecules, and has been found among the proteins downregulated by $\mathrm{E}_{2}$ treatment in our earlier proteomics study of the mouse uterus [24]. Overall, its biological role and previous experimental evidence have justified the inclusion of this protein as a prioritized candidate for targeted assay development for estrogenic ECDs.

The developed targeted assay for TGM2, EEF2, SELENBP1, and LUM using heavyisotope labeled peptides as internal standards are summarized in Table S3. Targeted proteomics was recognized as the method of the year in 2012 [51,52]. It is a specific and selective way to assay proteins of interest. Adapted from small-molecule methodologies and applied to targeted protein analyses, monitoring only selected proteotypic peptides facilitates an increase in sensitivity, reproducibility, as well as in specificity, and robustness when applied to a complex mixture of peptides obtained from a proteomics workflow. We developed the LC-MRM method for use with conventional high-performance liquid chromatography (HPLC, column i.d. of $2.1 \mathrm{~mm}$ ) to facilitate adaptation by laboratories not equipped with nanoflow LC capabilities.

We used the developed targeted proteomics assays for relative quantification in a study applied to BPA as a well-known example of estrogenic ECDs [34] using $E_{2}$ treatment as a positive control. BPA-based polymers such as polycarbonate plastics and epoxy resins 
are widely used [34]. BPA is a weak estrogenic EDC and has been a major target for endocrine disruption-related studies [53,54]. BPA can leach from plastic products and expose humans and the environment to its potentially harmful effects as an EDC [55-58]. Public concern about BPA exposure is so great because of its widespread use, and has led to a movement to specifically label products made without it as "BPA-free." As shown in Table 1, our targeted proteomics method allowed for determining quantitative changes of the chosen $\mathrm{E}_{2}$-regulated proteins in the rat uterus based on their proteotypic tryptic peptides across samples. Overall, changes in the expression of TGM2, EEF2, SELENBP1, and LUM replicated the trend observed from the wet uterus weight-based assessment displayed in Figure 3.

Table 1. $E_{2}$-regulated proteins in OVX rat uterus verified by targeted proteomics and applied to testing BPA [34,53-58] as a well-known estrogenic EDC.

\begin{tabular}{cccc}
\hline Rat Uterus Protein & Proteotypic Tryptic Peptide & ${\text { Fold Change after } \mathbf{E}_{\mathbf{2}} \text { Treatment }}^{\mathbf{1}}$ & Fold Change after BPA Treatment $^{\mathbf{1}}$ \\
\hline Transglutaminase 2, C & YSGCLTESNLIK & $24.7 \pm 4.6$ & $14.3 \pm 4.4$ \\
polypeptide (TGM2) & SEGTYCCGPVSVR & $17.5 \pm 2.3$ & $10.2 \pm 2.1$ \\
& EGIPALDNFLDKL & $3.9 \pm 0.3$ & $3.2 \pm 0.3$ \\
Elongation factor 2 (EEF2) & TFCQLILDPIFK & $8.4 \pm 1.1$ & $6.5 \pm 1.1$ \\
Selenium-binding protein 1 & HEIIQTLQMK & $-2.2 \pm 0.5$ & $-2.0 \pm 0.2$ \\
(SELENBP1) & LILPSIISSR & $-2.9 \pm 0.1$ & $-2.3 \pm 0.2$ \\
Lumican (LUM) & NNQIDHIDEK & $-3.8 \pm 0.8$ & $-6.3 \pm 0.8$ \\
& SLEYLDLSFNQMSK & $-2.0 \pm 0.4$ & $-2.5 \pm 0.1$ \\
\hline
\end{tabular}

${ }^{1}$ All reported results (data given as average \pm standard error) yielded statistically significant differences from OVX controls with analysis of variance (ANOVA) followed by post hoc Dunnett's tests, $p<0.05$.

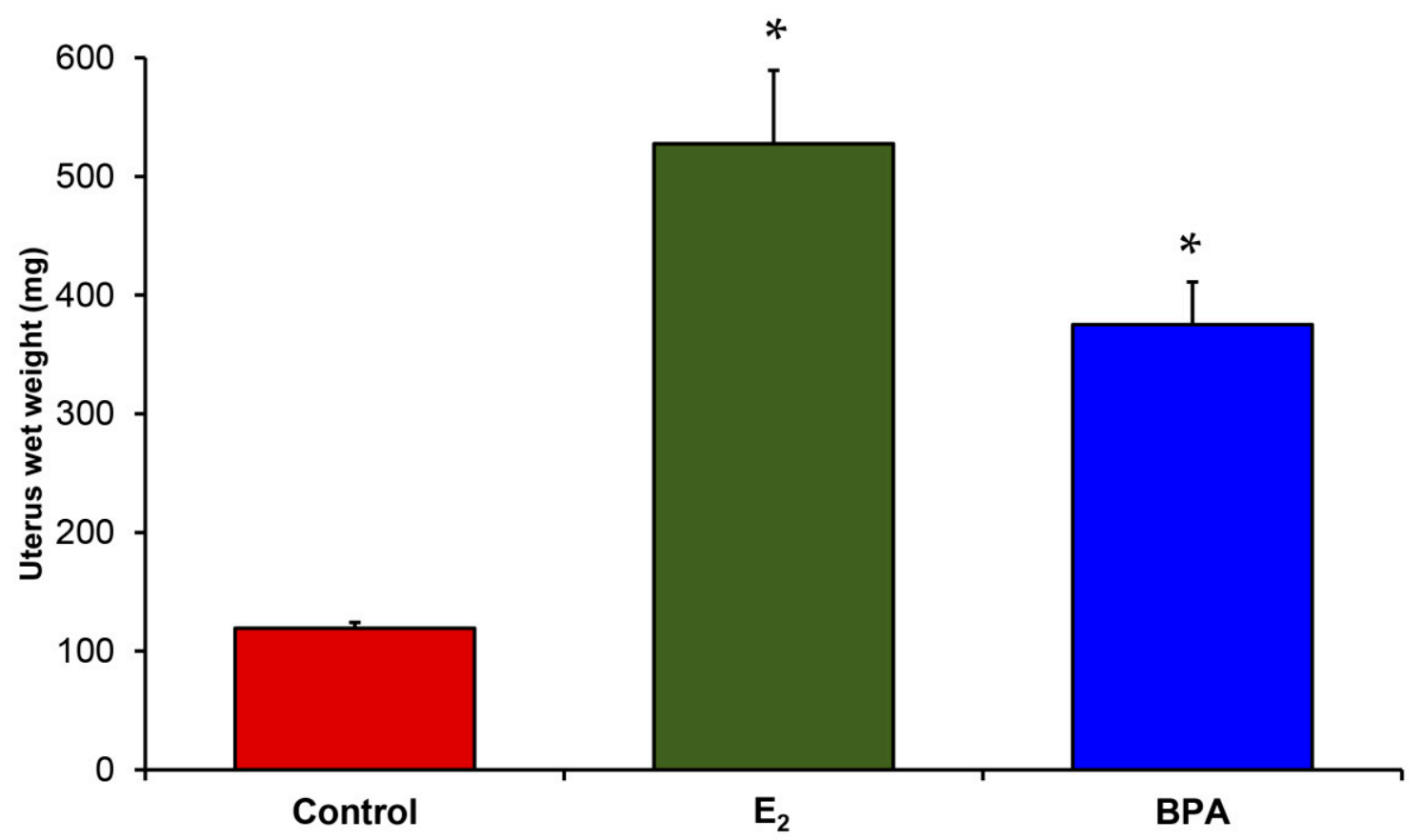

Figure 3. Uterus wet weights of $E_{2}$-treated and BPA-treated OVX Sprague-Dawley rats compared to vehicle-treated controls in the reported experiment. Data are given as average \pm standard error, and asterisks $\left(^{*}\right)$ indicate statistically significant differences from OVX controls with ANOVA followed by post hoc Dunnett's tests $(p<0.05)$. 
In conclusion, we presented differential proteome analyses focusing on estrogenregulated rat uterus proteins using quantitative proteomics approaches: first a label-free shotgun method followed by targeted quantitation as a roadmap for the complementation of the conventional uterotrophic assay. To our knowledge, this is the first study to identify and verify in vivo rat uterine protein markers for potential screening of candidate EDCs regarding effects that mimic those of estrogen.

\section{Materials and Methods}

\subsection{Chemicals}

All HPLC grade solvents were obtained from Fisher Scientific (Atlanta, GA, USA). Sequencing grade trypsin was from Applied Biosystems (Foster City, CA, USA). All other chemicals were acquired through Sigma-Aldrich (St. Louis, MO, USA) unless otherwise stated.

\subsection{Animals}

Sprague Dawley rats weighing 200-250 g were obtained from Charles Rivers Laboratories (Wilmington, DE, USA). They were kept under a standard $12 \mathrm{~h}$ light $/ 12 \mathrm{~h}$ dark cycle, and the room temperature was maintained at $21^{\circ} \mathrm{C}$. Ovariectomy of the rats was done by the supplier (Charles River Laboratories). Animals were shipped approximately one week after the procedure and allowed to adapt in the animal facility for approximately two weeks before starting their treatment. Two animals were housed per cage with full access to standard diet and water.

For discovery-driven proteomics, daily subcutaneous (s.c.) injections with the vehicle control (corn oil, $60 \mu \mathrm{L}$ per injection), or E2 (50 $\mu \mathrm{g} / \mathrm{kg}$ body weight in corn oil vehicle) were done on 5 consecutive days between 10:00 a.m. and 12:00 a.m., and the rats were killed for immediate tissue collection on the sixth day after starting the experiments. The targeted proteomics experiments were done using a separate cohort of animals with treatments identical as above and with an added group of OVX rats that received s.c. injections of BPA (300 mg/ $\mathrm{kg}$ body weight in corn oil vehicle). Except for the BPA group $(\mathrm{N}=5)$, each treatment group consisted of four animals. The animals were sacrificed by cervical dislocation, decapitated, and their brains were removed. An abdominal incision was then made and the uterus was removed by cutting at the junction of the uterus and vagina and at the site of the ovariectomy on each horn. Excess fat and connective tissues were removed, and the organ was blotted and weighed. All tissues were stored at $-80^{\circ} \mathrm{C}$ until sample preparation and analysis.

\subsection{Sample Preparation}

Tissues were incubated in $200 \mu \mathrm{L}$ of $8 \mathrm{M}$ urea for $30 \mathrm{~min}$, as reported before $[24,35]$. The samples were centrifuged for $5 \mathrm{~min}$ at $1400 \times g$ and the supernatant was collected. The protein content of uterine extracts was determined by a microBCA assay (Bio-RAD, Hercules, CA, USA). Approximately $100 \mu \mathrm{g}$ of protein from each sample was used for further processing. Samples were reduced with $1 \mathrm{mM}$ dithiothreitol (DTT) for $30 \mathrm{~min}$ at $65^{\circ} \mathrm{C}$ to reduce the disulfide bonds. Carbamidomethylation of the thiol groups was performed by the addition of $5 \mathrm{mM}$ iodoacetamide (IAA) and incubation for $30 \mathrm{~min}$ at room temperature in the dark. Excess IAA was quenched by the addition of DTT for 5 min. The samples were diluted with $50 \mathrm{mM}$ ammonium bicarbonate to lower the urea concentration to less than 2 M. Samples were digested with sequencing grade trypsin (1:50, Applied Biosystems, Foster City, CA) overnight. The tryptic digestion was terminated by acidifying the samples to $\mathrm{pH}<2.0$ with acetic acid and the digests were desalted using C18 Sep-Pak solid-phase extraction cartridges (Waters, Milford, MA, USA). The desalted uterine tryptic digests were further dried under vacuum (Vacufuge ${ }^{\mathrm{TM}}$, Eppendorf AG, Hamburg, Germany) and subsequently reconstituted in $20 \mu \mathrm{L}$ of $5 \%(v / v)$ acetonitrile in water containing $0.1 \%(v / v)$ acetic acid and aliquots of $5 \mu \mathrm{L}$ were used for LC-MS/MS analyses. 


\subsection{Data-Dependent LC-MS/MS Data Acquisition for Discovery-Driven Shotgun Proteomics}

The digested samples were analyzed using a hybrid ion trap-Orbitrap tandem mass spectrometer (LTQ Velos Orbitrap Pro) coupled to an EASY nLC-1000 nanoflow liquid chromatography system fitted with a $15 \mathrm{~cm} \times 75 \mu \mathrm{m}$ i.d. EasySpray column packed with $3 \mu \mathrm{m}$ PepMap C18 particles (Thermo Fisher Scientific, San Jose, CA, USA) [35]. Gradient elution was used: solvent $\mathrm{A}$ and solvent $\mathrm{B}$ were water and acetonitrile, respectively, and each contained $0.1 \%(v / v)$ formic acid. Samples (equivalent to $100 \mu \mathrm{g}$ protein) were reconstituted in $100 \mu \mathrm{L}$ of the solvent containing $5 \%(v / v)$ acetonitrile and $0.1 \%(v / v)$ formic acid in water and transferred into $200 \mu \mathrm{L}$ polypropylene autosampler vials closed with an open-top screw cap and Teflon-lined silicon septum (USA Scientific, Orlando, FL, USA). During a 20-min column equilibration at $5 \% \mathrm{~B}, 5 \mu \mathrm{L}$ of the solution was injected while maintaining constant column pressure at 600 bar. The peptides were eluted at $300 \mathrm{~nL} / \mathrm{min}$ using the following gradient: (1) $5 \mathrm{~min}$ isocratic at $5 \% \mathrm{~B}$; (2) linear program to $40 \%$ B over $90 \mathrm{~min}$ and then (3) isocratic at $40 \%$ B for $5 \mathrm{~min}$; (4) to $90 \%$ B over $5 \mathrm{~min}$; (6) isocratic at $90 \% \mathrm{~B}$ for $5 \mathrm{~min}$; and (6) resetting to $5 \% \mathrm{~B}$ in $20 \mathrm{~min}$. The mass spectrometer was operated in positive-ion nanoelectrospray (nanoESI) mode with a source voltage of $2.0 \mathrm{kV}$ and ion-transfer tube temperature of $275^{\circ} \mathrm{C}$. Full-scan mass spectra were acquired at 60,000 resolution $(\mathrm{m} / \mathrm{z} 400)$ in the Orbitrap and up to $20 \mathrm{MS} / \mathrm{MS}$ spectra were obtained in the ion trap for each full spectrum acquired using collision-induced dissociation (CID) of multiply-charged ions $(\mathrm{z} \geq 2)$. Dynamic exclusion was set for $60 \mathrm{~s}$ after an ion was selected for fragmentation. Two technical replicates were run for each sample.

\subsection{Database Search, Label-Free Relative Quantification, and Pathway Analysis}

MS/MS spectra were searched against the UniProt protein sequence database (species: Rattus norvegicus, 29,938 entries) using the Mascot search engine (version 2.6.2; Matrix Science, Boston, MA, USA) run from Proteome Discoverer (version 2.3; Thermo Fisher Scientific). A parent ion mass tolerance and fragment ion mass tolerance were set to $25 \mathrm{ppm}$ and $0.80 \mathrm{Da}$, respectively, allowing only one missed cleavage in our search filters and limiting FDR to $0.01(1 \%)$. Cystein carbamidomethylation was indicated as fixed modification and methionine oxidation was designated as variable modification. We used Scaffold software (version 4.9.0, Proteome Software Inc.; Portland, OR, USA) to validate our search results using the Peptide Prophet [36] and Protein Prophet [37] algorithms requiring over $95 \%$ and $99 \%$ probabilities, respectively, and at least two identified unique peptides for each protein. Our LFQ relied on SC [23] built into the Scaffold software, and $p<0.05$ was considered significantly different using unpaired $t$-tests for statistical comparison between sample categories. We also considered a twofold change in spectral counts as a threshold of biological effect. Missing values, if any, were handled using Scaffold's default method and settings. The identified $E_{2}$-regulated proteins were submitted to Ingenuity Pathway Analysis ${ }^{\circledR}\left(\right.$ IPA $^{\circledR}$, QIAGEN, Redwood City, CA, USA; https:/ / www.qiagenbioinformatics. $\mathrm{com} /$ products/ingenuity-pathway-analysis/) (accessed on 12 January 2021) to derive bioinformatics annotations along with potential protein interaction networks, as well as associated biological functions and processes. Overlaps of $p$-values were reported from $\mathrm{IPA}^{\circledR}{ }^{\circledR}$ s calculations using the right-tailed Fisher's exact test.

\subsection{Target Panel and Internal Standards}

Two proteotypic peptides were selected and subjected to BLASTP analysis for each protein (TGM2, EEF2, SELENBP1, and LUM) to confirm 100\% homology. The selected peptides did not have any missed cleavages and did not have extensive post-translational modifications. Carbamidomethylated cysteine was incorporated as a fixed modification in all peptides when required. The approach involved the use of stable-isotope labeled internal standards (SIS) added to the tissue extracts for comparison against native tryptic peptide (NAT) levels in the digested samples. The SIS peptides were purchased from New England Peptide (Gardner, MA, USA). Incorporation of the ${ }^{13} \mathrm{C}$ - and ${ }^{15} \mathrm{~N}$-isotopes was done at the C-terminal residue of tryptic peptides yielding mass shifts of $+8 \mathrm{Da}$ (from ${ }^{13} \mathrm{C}_{6}{ }^{15} \mathrm{~N}_{2}$ - 
lysine), $+10 \mathrm{Da}$ (from ${ }^{13} \mathrm{C}_{6}{ }^{15} \mathrm{~N}_{4}$-arginine), and $+7 \mathrm{Da}$ (from ${ }^{13} \mathrm{C}_{6}{ }^{15} \mathrm{~N}$-leucine) compared to their unlabeled counterparts in the samples.

\subsection{MRM-Based LC-MS/MS Data Acquisition for Targeted Proteomics}

Samples were analyzed in triplicate using a TSQ Quantum Ultra tripe-quadrupole mass spectrometer (TSQ, Thermo Electron Corporation, Trace Chemical Analysis, Austin, TX, USA) equipped with a heated electrospray ionization (H-ESI) source and operated with Xcalibur (version 2.2) and Tune Plus (version 2.2) data acquisition software.

Gradient HPLC separations were carried out using a Surveyor MS solvent delivery system (Thermo). The Phenomenex (Torrance, CA, USA) Aeris ${ }^{\mathrm{TM}}$ PEPTIDE XB-C18 column $(15 \mathrm{~cm} \times 2.1 \mathrm{~mm}$ i.d., packed with $3.6-\mu \mathrm{m}$ core-shell particles) was operated at $0.4 \mathrm{~mL} / \mathrm{min}$ flow rate and with the following gradient program: $2 \% \mathrm{~B}$ to $65 \% \mathrm{~B}$ in $30 \mathrm{~min}$, then ramped to $95 \% \mathrm{~B}$ in $0.5 \mathrm{~min}$ and held for $3.5 \mathrm{~min}$, and finally, the column was ramped to $2 \% \mathrm{~B}$ in $0.5 \mathrm{~min}$ and equilibrated for $10.5 \mathrm{~min}$. The autosampler injection volume was $10 \mu \mathrm{L}$, and the tray temperature was maintained at $18^{\circ} \mathrm{C}$. H-ESI spray voltage, $\mathrm{H}$-ESI temperature, and capillary temperature were $3.5 \mathrm{kV}, 275^{\circ} \mathrm{C}$, and $300{ }^{\circ} \mathrm{C}$, respectively. Nitrogen sheath gas and auxiliary gas flow rates were 30 and 20 arbitrary units (corresponding to approximately 0.45 and $6.0 \mathrm{~L} / \mathrm{min}$ according to the manufacturer's specification), respectively. CID was performed with argon at $1.5 \mathrm{mTorr}$ pressure. MRM with a unit mass resolution for the precursor and product ions was used for the quantitation of peptides. Data acquisition and processing were controlled by the XCalibur software (version 2.1) of the instrument. A complete list of the MRM transitions used in this study is provided in Supplementary Table S3.

\subsection{Data Processing for Targeted Proteomics and Statistical Analysis of the Results}

Manual verification of the extracted ion chromatogram peak selections was performed with XCalibur software (version 2.1). The area under the curve (AUC) of the relative abundance of each peak for each transition was calculated from within the Xcalibur software. Relative quantitation was done by first taking the average from the technical replicates of all samples for each peptide, and then using the ratio of NAT to SIS peptide, comparing controls and treated samples to get fold change increase or decrease. Relative ratios of SIS internal standards to endogenous peptide, for each peptide, were normalized to the control to get fold change differences.

Statistical analysis of the relative fold change of peptides was performed using ANOVA followed by post hoc Dunnett's tests. $p<0.05$ was considered statistically significant.

Supplementary Materials: The Supplementary Materials are available online at https:/ www.mdpi. com/1422-0067/22/4/1686/s1.

Author Contributions: Conceptualization, L.P.; methodology, F.R., K.Z., V.N., and L.P.; formal analysis, F.R., K.Z. and L.P.; investigation, F.R., K.Z., V.N., K.P.-T. and L.P.; resources, L.P. and K.P.-T.; writing-original draft preparation, F.R. and L.P.; writing—review and editing, L.P. and K.P.-T.; supervision, L.P.; project administration, L.P.; funding acquisition, L.P., K.P.-T. and F.R. All authors have read and agreed to the published version of the manuscript.

Funding: This research was funded by The Welch Foundation (endowment BK-0031 to L.P.), the National Institutes of Health (grants AG031535 to L.P., and EY027005 to K.P.-T.) and a predoctoral bridge funding by the Graduate School of Biomedical Sciences at the University of North Texas Health Science Center (to F.R.).

Institutional Review Board Statement: Procedures involving animals were approved by the Institutional Animal Care and Use Committee at the University of North Texas Health Science Center (USDA Registration Number: 74-R0081; PHS Assurance Number: A3711-01; AAALAC Accreditation Status: Unit 000622, continued full accreditation most recently on July 6, 2017) under the project numbers 2011/12-28-A05, 2014/15-22-A05 and IACUC-2018-0006 approved on 29 June 2012, 12 March 2015 and 26 March 2018, respectively.

Informed Consent Statement: Not applicable. 
Data Availability Statement: The mass spectrometry proteomics data have been deposited to the ProteomeXchange Consortium via the PRIDE [59] partner repository with the dataset identifier PXD023273 and doi:10.6019/PXD023273.

Acknowledgments: The authors thank Szabolcs Szarka for participation in the initial effort of the targeted proteomics experiments, and Shastazia White for assistance with animal care and maintenance.

Conflicts of Interest: The authors declare no conflict of interest.

\section{References}

1. Colborn, T.; vom Saal, F.S.; Soto, A.M. Developmental effects of endocrine-disrupting chemicals in wildlife and humans. Environ. Health Perspect. 1993, 101, 378-384. [CrossRef]

2. Ankley, G.; Francis, E.; Gray, E.; Kavlock, R.; McMaster, S.; Reese, D.; Sayles, G.; Sergeant, A.; Vallero, D. Research Plan for Endocrine Disruptors; Office of Research and Development, United States Environmental Protection Agency: Washington, DC, USA, 1998; pp. 1-47.

3. United States Environmental Protection Agency. Endocrine Disruptor Screening Program (EDSP). Available online: http: //www.epa.gov/endo/ (accessed on 27 October 2018).

4. United States Environmental Protection Agency. Next Generation Risk Assessment: Incorporation of Recent Advances in Molecular, Computational, and Systems Biology; National Center for Environmental Assessment Office of Research and Development, United States Environmental Protection Agency: Washington, DC, USA, 2014; pp. 1-12.

5. Baker, V.A. Endocrine disrupters-Testing strategies to assess human hazard. Toxicol. Vitr. 2001, 15, 413-419. [CrossRef]

6. Clode, S.A. Assessment of in vivo assays for endocrine disruption. Best Pract. Res. Clin. Endocrinol. Metab. 2006, 20, 35-43. [CrossRef]

7. Gelbke, H.P.; Kayser, M.; Poole, A. OECD test strategies and methods for endocrine disruptors. Toxicology 2004, 205, 17-25. [CrossRef] [PubMed]

8. Marty, M.S.; O'Connor, J.C. Key learnings from the Endocrine Disruptor Screening Program (EDSP) Tier 1 rodent uterotrophic and Hershberger assays. Birth Defects Res. Dev. Reprod. Toxicol. 2014, 101, 63-79. [CrossRef]

9. Owens, J.W.; Ashby, J. Critical review and evaluation of the uterotrophic bioassay for the identification of possible estrogen agonists and antagonists: In support of the validation of the OECD uterotrophic protocols for the laboratory rodent. Crit. Rev. Toxicol. 2002, 32, 445-520. [CrossRef] [PubMed]

10. O'Connor, J.C.; Cook, J.C.; Marty, M.S.; Davis, L.G.; Kaplan, A.M.; Carney, E.W. Evaluation of Tier I screening approaches for detecting endocrine-active compounds (EACs). Crit. Rev. Toxicol. 2002, 32, 521-549. [CrossRef]

11. Yoon, K.; Kwack, S.J.; Kim, H.S.; Lee, B.M. Estrogenic endocrine-disrupting chemicals: Molecular mechanisms of actions on putative human diseases. J. Toxicol. Environ. Health Crit. Rev. 2014, 17, 127-174. [CrossRef]

12. Kiyama, R.; Wada-Kiyama, Y. Estrogenic endocrine disruptors: Molecular mechanisms of action. Environ. Int. 2015, 83, 11-40. [CrossRef] [PubMed]

13. Tyler, C.R.; Jobling, S.; Sumpter, J.P. Endocrine disruption in wildlife: A critical review of the evidence. Crit. Rev. Toxicol. 1998, 28, 319-361. [CrossRef] [PubMed]

14. United States Environmental Protection Agency. Endocrine Disruptor Screening Program Test Guidelines OPPTS 890.1600: Uterotrophic Assay; Office of Prevention, Pesticides and Toxic Substances (OPPTS), United States Environmental Protection Agency: Washington, DC, USA, 2009; pp. 1-21.

15. United States Environmental Protection Agency. Uterotrophic Assay OCSPP Guideline 890.1600: Standard Evaluation Procedure (SEP); Endocrine Disruptor Screening Program, United States Environmental Protection Agency: Washington, DC, USA, 2011; pp. 1-19.

16. Watanabe, H.; Suzuki, A.; Kobayashi, M.; Takahashi, E.; Itamoto, M.; Lubahn, D.B.; Handa, H.; Iguchi, T. Analysis of temporal changes in the expression of estrogen-regulated genes in the uterus. J. Mol. Endocrinol. 2003, 30, 347-358. [CrossRef]

17. Watanabe, H.; Suzuki, A.; Mizutani, T.; Khono, S.; Lubahn, D.B.; Handa, H.; Iguchi, T. Genome-wide analysis of changes in early gene expression induced by oestrogen. Genes Cells 2002, 7, 497-507. [CrossRef]

18. Bauersachs, S.; Mitko, K.; Ulbrich, S.E.; Blum, H.; Wolf, E. Transcriptome studies of bovine endometrium reveal molecular profiles characteristic for specific stages of estrous cycle and early pregnancy. Exp. Clin. Endocrinol. Diabetes 2008, 116, 371-384. [CrossRef] [PubMed]

19. Zama, A.M.; Uzumcu, M. Epigenetic effects of endocrine-disrupting chemicals on female reproduction: An ovarian perspective. Front. Neuroendocrinol. 2010, 31, 420-439. [CrossRef] [PubMed]

20. Spencer, T.E.; Dunlap, K.A.; Filant, J. Comparative developmental biology of the uterus: Insights into mechanisms and developmental disruption. Mol. Cell. Endocrinol. 2012, 354, 34-53. [CrossRef]

21. La Rocca, J.; Boyajian, A.; Brown, C.; Smith, S.D.; Hixon, M. Effects of in utero exposure to Bisphenol A or diethylstilbestrol on the adult male reproductive system. Birth Defects Res. Dev. Reprod. Toxicol. 2011, 92, 526-533. [CrossRef]

22. Sahambi, S.K.; Pelland, A.; Cooke, G.M.; Schrader, T.; Tardif, R.; Charbonneau, M.; Krishnan, K.; Haddad, S.; Cyr, D.G.; Devine, P.J. Oral p-tertoctylphenol exposures induce minimal toxic or estrogenic effects in adult female Sprague-Dawley rats. J. Toxicol. Environ. Health 2010, 73, 607-622. [CrossRef] [PubMed] 
23. Seidlova-Wuttke, D.; Christoffel, J.; Rimoldi, G.; Jarry, H.; Wuttke, W. Comparison of effects of estradiol with those of octylmethoxycinnamate and 4-methylbenzylidene camphor on fat tissue, lipids and pituitary hormones. Toxicol. Appl. Pharmacol. 2006, 214, 1-7. [CrossRef] [PubMed]

24. Prokai, L.; Stevens, S.M., Jr.; Rauniyar, N.; Nguyen, V. Rapid label-free identification of estrogen-induced differential protein expression in vivo from mouse brain and uterine tissue. J. Proteome Res. 2009, 8, 3862-3871. [CrossRef] [PubMed]

25. Callegari, E.A. Shotgun proteomics analysis of estrogen effects in the uterus using two-dimensional liquid chromatography and tandem mass spectrometry. Methods Mol. Biol. 2016, 1366, 131-148.

26. Aebersold, R.; Goodlett, D.R. Mass spectrometry in proteomics. Chem. Rev. 2001, 101, 269-295. [CrossRef] [PubMed]

27. Aebersold, R.; Mann, M. Mass spectrometry-based proteomics. Nature 2003, 422, 198-207. [CrossRef]

28. Bantscheff, M.; Schirle, M.; Sweetman, G.; Rick, J.; Kuster, B. Quantitative mass spectrometry in proteomics: A critical review. Anal. Bioanal. Chem. 2007, 389, 1017-1031. [CrossRef]

29. Bantscheff, M.; Lemeer, S.; Savitski, M.M.; Kuster, B. Quantitative mass spectrometry in proteomics: Critical review update from 2007 to the present. Anal. Bioanal. Chem. 2012, 404, 939-965. [CrossRef]

30. Bensimon, A.; Heck, A.J.R.; Aebersold, R. Mass Spectrometry-Based Proteomics and Network Biology. In Annual Review of Biochemistry; Kornberg, R.D., Ed.; Annual Reviews: Palo Alto, CA, USA, 2012; Volume 81, pp. 379-405.

31. Ebhardt, H.A.; Root, A.; Sander, C.; Aebersold, R. Applications of targeted proteomics in systems biology and translational medicine. Proteomics 2015, 15, 3193-3208. [CrossRef]

32. Shi, T.J.; Song, E.W.; Nie, S.; Rodland, K.D.; Liu, T.; Qian, W.J.; Smith, R.D. Advances in targeted proteomics and applications to biomedical research. Proteomics 2016, 16, 2160-2182. [CrossRef]

33. Doerr, A. Mass spectrometry-based targeted proteomics. Nat. Methods 2013, 10, 23. [CrossRef]

34. Abraham, A.; Chakraborty, P. A review on sources and health impacts of bisphenol A. Rev. Environ. Health 2020, 35, 201-210. [CrossRef]

35. Prokai, L.; Zaman, K.; Nguyen, V.; Prokai-Tatrai, K. 17 $\beta$-Estradiol delivered in eye drops: Evidence of impact on protein networks and associated biological processes in the rat retina through quantitative proteomics. Pharmaceutics 2020, 12, 101. [CrossRef] [PubMed]

36. Keller, A.; Nesvizhskii, A.I.; Kolker, E.; Aebersold, R. Empirical statistical model to estimate the accuracy of peptide identifications made by MS/MS and database search. Anal. Chem. 2002, 74, 5383-5392. [CrossRef] [PubMed]

37. Nesvizhskii, A.I.; Keller, A.; Kolker, E.; Aebersold, R. A statistical model for identifying proteins by tandem mass spectrometry. Anal. Chem. 2003, 75, 4646-4658. [CrossRef]

38. Liu, H.; Sadygov, R.G.; Yates, J.R., III. A model for random sampling and estimation of relative protein abundance in shotgun proteomics. Anal. Chem. 2004, 76, 4193-4201. [CrossRef]

39. Kerdivel, G.; Habauzit, D.; Pakdel, F. Assessment and molecular actions of endocrine-disrupting chemicals that interfere with estrogen receptor pathways. Int. J. Endocrinol. 2013, 2013, 501851. [CrossRef]

40. Jaffe, J.D.; Keshishian, H.; Chang, B.; Addona, T.A.; Gillette, M.A.; Carr, S.A. Accurate inclusion mass screening. Mol. Cell. Proteom. 2008, 7, 1952-1962. [CrossRef] [PubMed]

41. Roepstorff, P.; Fohlman, J. Proposal for a common nomenclature for sequence ions in mass spectra of peptides. Biomed. Mass Spectrom. 1984, 11, 601. [CrossRef] [PubMed]

42. Boverhof, D.R.; Fertuck, K.C.; Burgoon, L.D.; Eckel, J.E.; Gennings, C.; Zacharewski, T.R. Temporal- and dose-dependent hepatic gene expression changes in immature ovariectomized mice following exposure to ethynyl estradiol. Carcinogenesis 2004, 25, 1277-1291. [CrossRef]

43. Kiraly, R.; Demeny, M.; Fesus, L. Protein transamidation by transglutaminase 2 in cells: A disputed Ca ${ }^{2+}$-dependent action of a multifunctional protein. FEBS J. 2011, 278, 4717-4739. [CrossRef]

44. Zhu, Z.; Boobis, A.R.; Edwards, R.J. Identification of estrogen-responsive proteins in MCF-7 human breast cancer cells using label-free quantitative proteomics. Proteomics 2008, 8, 1987-2005. [CrossRef]

45. Collodoro, M.; Lemaire, P.; Eppe, G.; Bertrand, V.; Dobson, R.; Mazzucchelli, G.; Widart, J.; De Pauw, E.; De Pauw-Gillet, M.C. Identification and quantification of concentration-dependent biomarkers in MCF-7/BOS cells exposed to 17beta-estradiol by 2-D DIGE and label-free proteomics. J. Proteom. 2012, 75, 4555-4569. [CrossRef]

46. Øverbye, A.; Brinchmann, M.F.; Seglen, P.O. Proteomic analysis of membrane-associated proteins from rat liver autophagosomes. Autophagy 2014, 3, 300-322. [CrossRef]

47. Zhang, Z.; Zhang, J.; Xiao, J. Selenoproteins and selenium status in bone physiology and pathology. Biochim. Biophys. Acta 2014, 1840, 3246-3256. [CrossRef]

48. Porat, A.; Sagiv, Y.; Elazar, Z. A 56-kDa Selenium-binding protein participates in intra-Golgi protein transport. J. Biol. Chem. 2000, 275, 14457-14465. [CrossRef] [PubMed]

49. Zhang, S.; Li, F.; Younes, M.; Liu, H.; Chen, C.; Yao, Q. Reduced selenium-binding protein 1 in breast cancer correlates with poor survival and resistance to the anti-proliferative effects of selenium. PLoS ONE 2013, 8, e63702. [CrossRef] [PubMed]

50. Salgado, R.M.; Favaro, R.R.; Zorn, T.M.T. Modulation of small leucine-rich proteoglycans (SLRPs) expression in the mouse uterus by estradiol and progesterone. Reprod. Biol. Endocrinol. 2011, 9, 22. [CrossRef] [PubMed]

51. Anonymous. Method of the Year 2012. Nat. Methods 2013, 10, 1. [CrossRef]

52. Marx, V. Targeted proteomics. Nat. Methods 2012, 10, 19-22. [CrossRef] 
53. Kim, H.S.; Han, S.Y.; Yoo, S.D.; Lee, B.M.; Park, K.L. Potential estrogenic effects of bisphenol-A estimated by in vitro and in vivo combination assays. J. Toxicol. Sci. 2001, 26, 111-118. [CrossRef]

54. Kitamura, S.; Suzuki, T.; Sanoh, S.; Kohta, R.; Jinno, N.; Sugihara, K.; Yoshihara, S.; Fujimoto, N.; Watanabe, H.; Ohta, S. Comparative study of the endocrine-disrupting activity of bisphenol A and 19 related compounds. Toxicol. Sci. 2005, 84, 249-259. [CrossRef]

55. Rochester, J.R. Bisphenol A and human health: A review of the literature. Reprod. Toxicol. 2013, 42, 132-155. [CrossRef]

56. Liao, C.; Kannan, K. Concentrations and profiles of bisphenol A and other bisphenol analogues in foodstuffs from the United States and their implications for human exposure. J. Agric. Food Chem. 2013, 61, 4655-4662. [CrossRef] [PubMed]

57. Bhandari, R.K.; Deem, S.L.; Holliday, D.K.; Jandegian, C.M.; Kassotis, C.D.; Nagel, S.C.; Tillitt, D.E.; Vom Saal, F.S.; Rosenfeld, C.S. Effects of the environmental estrogenic contaminants bisphenol A and $17 \alpha$-ethinyl estradiol on sexual development and adult behaviors in aquatic wildlife species. Gen. Comp. Endocrinol. 2015, 214, 195-219. [CrossRef]

58. Bisphenol A (BPA). Available online: https://www.niehs.nih.gov/health/topics/agents/sya-bpa/ (accessed on 21 January 2021).

59. Vizcaino, J.A.; Deutsch, E.W.; Wang, R.; Csordas, A.; Reisinger, F.; Rios, D.; Dianes, J.A.; Sun, Z.; Farrah, T.; Bandeira, N.; et al. Proteome Xchange provides globally coordinated proteomics data submission and dissemination. Nat. Biotechnol. 2014, 32, 223-226. [CrossRef] 